\title{
Experimental investigation on the dynamic compressive characteristics of tungsten-fibre/Zr-based BMGC
}

\author{
G. Chen \& X. Chen \\ Institute of Systems Engineering, \\ China Academy of Engineering Physics, China
}

\begin{abstract}
Bulk metallic glass (BMG) alloys have attractive mechanical properties for structural applications, and tungsten fibre reinforced bulk metallic glass matrix composite (BMGC) would further improve the properties compared to unreinforced BMG. Mechanical properties of Zr-based BMG reinforced with $80 \%$ tungsten fibres by volume are experimentally investigated in the present study at ambient temperature and elevated temperature up to $600^{\circ} \mathrm{C}$. From static tests at different temperatures, it is observed that yield stress of BMGC decreases with temperature, and the strain hardening behaviour at ambient temperature vanishes at an elevated temperature. At ambient temperature the dynamic yield stress of BMGC from SHPB tests is approximately 30\% higher than the quasi-static counterpart. However, the specimens in SHPB tests are found to have smaller strain capacity. Dynamic yield stresses are also found to decrease with the elevation of temperature. Based on the test data, an empirical formula is proposed to describe the change of yield stress due to temperature elevation.
\end{abstract}

Keywords: bulk metallic glass, tungsten fibre, mechanical properties, split Hopkinson pressure bar, elevated temperature.

\section{Introduction}

Bulk metallic glass (BMG) is produced by extremely sharp cooling from the liquid alloy, which hinders the crystallisation kinetics, and the material maintains as an amorphous state. Through the monolithic BMG materials have the excellent mechanical property of high strength, but they are lack of plastic deformation and 
exhibit catastrophic failure due to highly localised shear bands [1-4]. This defect significantly limits the application of BMGs in engineering applications, and bring motivation to improve the ductility of these monolithic BMG materials. BMG based composites developed by adding discrete particles or fibres as reinforcement to hinder the propagation of single shear band and develop multiple shear bands in BMG material [5-8].

The experimental study on quasi-static and dynamic compressive behaviours

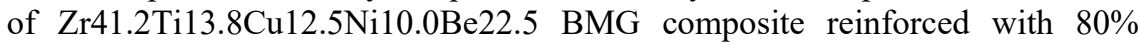
volume fraction $\left(\mathrm{V}_{\mathrm{f}}\right)$ of tungsten fibres at ambient and elevated temperatures is presented in this paper. The behaviours and properties of the composite is investigated and discussed.

\section{Experimental programme}

From Ø8.5-150 mm BMG composite ingots, cylindrical specimens were machined, with axis parallel to the fibre direction. The composite density is $17.5 \mathrm{~g} / \mathrm{cm}^{3}$. The specimens were polished mechanically before being tested. Microscopic image of specimen cross section is given in Figure 1. The compatibility of the W-BMG composite can be observed. The cross section shows nearly close packed tungsten fibres in the BMG matrix.

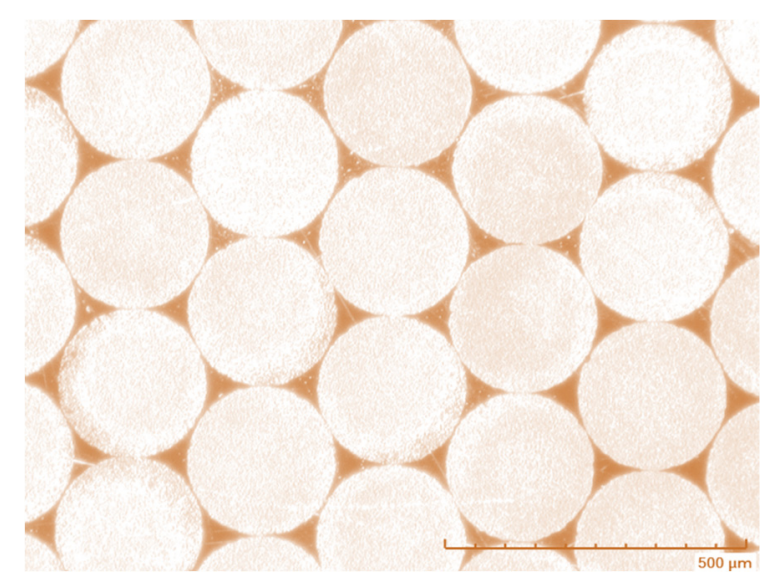

Figure 1: Microscopic image of specimen cross section.

Quasi-static compressive tests at ambient temperature of $20^{\circ} \mathrm{C}$ were conducted by using universal testing machine INSTRON 1196 while tests at elevated temperature were carried out on a computer-controlled, servo-hydraulic testing machine MTS 810 with the temperature controlled furnace. The loading speed in quasi-static tests was controlled at $0.5 \mathrm{~mm} / \mathrm{min}$.

At a high strain rate, Split Hopkinson pressure bar (SHPB) testing system was used to study the dynamic compressive behaviour of the Zr-based BMG with tungsten fibre reinforcements. In a typical SHPB apparatus, the impact of the striker bar at the free end of the incident bar develops a compressive longitudinal 
incident wave. Once this wave reaches the bar - specimen interface, a part of it is reflected, while another part goes through the specimen and develops the transmitted wave in the transmitted bar.

According to the basic theory of one-dimension compressive wave, the stress, strain, and strain-rate of the testing specimen can be represented by the following equations.

$$
\begin{gathered}
\sigma(t)=E\left(\frac{A_{B}}{A_{S}}\right) \varepsilon_{T}(t) \\
\varepsilon(t)=-\frac{2 C_{0}}{L} \int_{0}^{T} \varepsilon_{R}(t) d t \\
\dot{\varepsilon}(t)=-\frac{2 C_{0}}{L} \varepsilon_{R}(t)
\end{gathered}
$$

where $A_{s}$ and $\mathrm{L}$ are the area of cross section and length of specimens; E, $\mathrm{C}_{0}$ and $A_{B}$ are the modulus of elasticity, area of cross section and speed of elastic wave of pressure bars; and $\varepsilon_{\mathrm{T}}$ and $\varepsilon_{\mathrm{R}}$ represent the transmitted and reflected strain, respectively.

In the SHPB system presented in this paper, the diameter of bars is $25 \mathrm{~mm}$. The lengths of striker bar, incident bar and transmitted bar are 300, 2000 and $2000 \mathrm{~mm}$, respectively. Strain gauges were glued at midpoints of pressure bars.

A temperature-controlled furnace was used in the SHPB system as shown in figure 2 to investigate the dynamic material behaviour at elevated temperature [ 9 , 10]. The specimen is heated in the furnace alone. The system was assembled and impact test was carried out after reaching and stabilising at the desired temperature, so that the thermal effect on pressure bars was minimized.

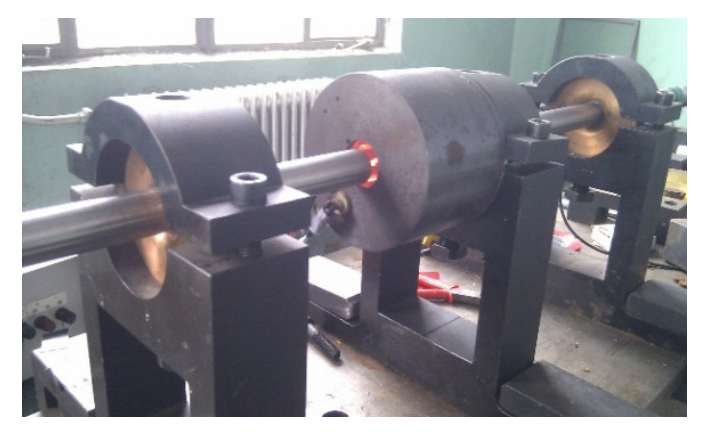

Figure 2: Furnace in the SHPB system.

In order to avoid significant oscillation and dispersion during the stress wave translation and assure the equilibrium stress state in the specimen, vacuum cement was used as pulse shaper at the impact end of the incident pressure bar as suggested in [11]. 


\section{Test results}

\subsection{Quasi-static tests}

\subsubsection{Tests at ambient temperature}

Cylindrical specimens were prepared and tested with aspect ratios (ratio of length to diameter) of 2,1 and 0.5 , respectively. Figure 3 gives the obtained stress-strain curves.

It can be seen from the figure that, the pre-yielding curves are consistent irrespective at the different aspect ratios of specimens with a yield stress of $2300 \mathrm{MPa}$ and a yield strain of 0.025 . All specimens exhibit large ductility with more than $20 \%$ strain, demonstrating the significant role of tungsten fibres in the deformation behaviour of the composite. This result is consistent with the findings of other researchers [4].

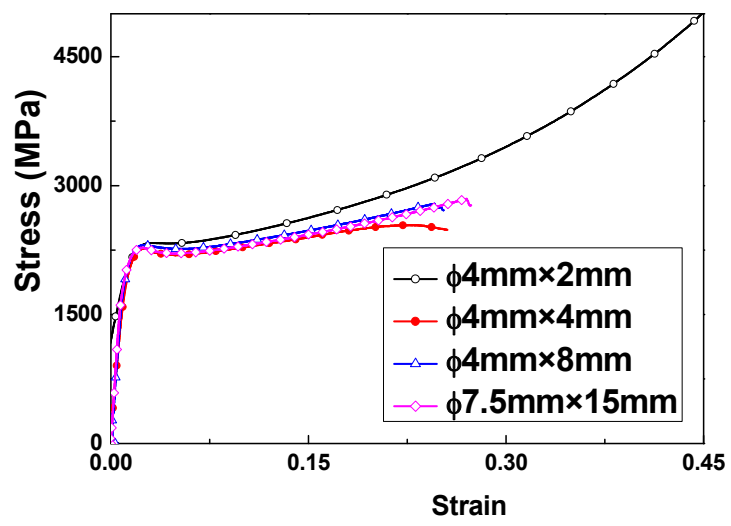

Figure 3: $\quad$ Stress-strain curves of specimens with different aspect ratios.

It is also found in Figure 3 that in the post-yielding range, specimens with aspect ratios of 1 and 2 have clear failure indications and similar stress - strain relations. However, the specimen with aspect ratio of 0.5 exhibits significantly higher stress without clear damage. This is confirmed by comparing the final deformation and failure formation of specimens in Figure 4. The specimen with aspect ratio of 1 is found to undergo axial splitting and buckling. Specimen with aspect ratio of 0.5 is found to have significant compressive deformation without clear damage. This indicates that multi-axial stress state induced by the end-friction has significant influence on the mechanical behaviour of specimens with aspect ratio smaller than 1.0, thus the corresponding results cannot be used to represent the mechanical properties of such composite materials. Therefore, the static stress-strain curve of $\varnothing 4 \times 8 \mathrm{~mm}$ specimen at ambient temperature is used as reference for investigating the influence of temperature and strain rate. 


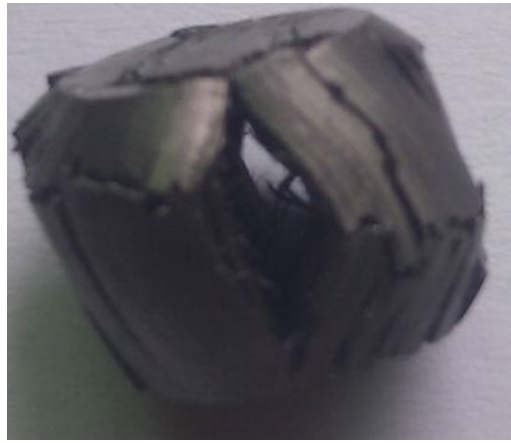

(a)

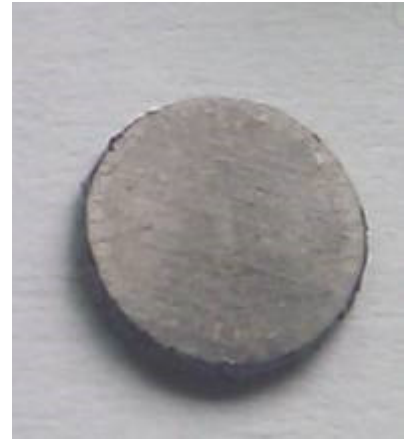

(b)

Figure 4: Deformation and failure formation of specimens with aspect ratio of (a) 1 and (b) 0.5 .

\subsubsection{Tests at elevated temperature}

To investigate the effect of temperature on mechanical properties of the composite, high-temperature compressive tests of the tungsten fibre reinforced $\mathrm{BMG}$ composite were performed at $150^{\circ} \mathrm{C}$ and $300^{\circ} \mathrm{C}$. During the tests, the specimens at high temperatures were observed to have bending deformation after reaching the yield stress. The stress-strain curves of specimens at corresponding elevated temperatures are given in figure 5. For comparison purpose, stress-strain relation of specimen at ambient temperature is also included in the figure. It can be seen that, compared to the result at ambient temperature $\left(20^{\circ} \mathrm{C}\right)$, the yield strengths of the composite at $150^{\circ} \mathrm{C}$ and $300^{\circ} \mathrm{C}$ have the reduction of $9 \%$ and $22 \%$, with stress of $2100 \mathrm{MPa}$ and $1800 \mathrm{MPa}$, respectively. Moreover, the behaviour of strain hardening at ambient temperature in the post-yielding range disappears at elevated temperatures, indicating the significant dependence of the mechanical properties of BMG composites on temperature.

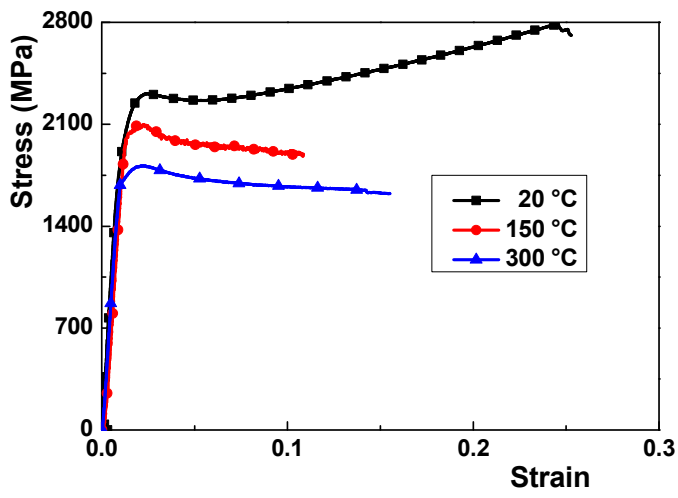

Figure 5: Stress-strain curves of BMGC at different temperatures. 


\subsection{SHPB tests}

\subsubsection{Tests at ambient temperature}

The strain rate, strain and stress can be obtained by analysing strain signals on pressure bars in SHPB tests as mentioned above. The comparison of stress strain curves between quasi-static and dynamic at ambient temperature (about $20^{\circ} \mathrm{C}$ ) is given in Fig. 6a. It can be seen that the dynamic stress-strain relations are about $30 \%$ higher than that under quasi-static loading condition. However, the difference of the dynamic yield stress in the strain rate range between $450 \mathrm{~s}^{-1}$ and $2000 \mathrm{~s}^{-1}$ seems insignificant. A constitutive equation suggested by Cowper and Symonds can be used to describe the material strain rate sensitivity as [12]

$$
\sigma_{d} / \sigma_{s}=1+\left(\frac{\dot{\varepsilon}}{D}\right)^{1 / q}
$$

where $\sigma_{d}$ is the dynamic yield stress at a strain rate $\dot{\varepsilon}, \sigma_{s}$ is the associated static yield stress, D and $\mathrm{q}$ are constants for a particular material. The scattered yield stresses with respect to strain rate are given in Fig. 6(b), and the solid line represents the fitting result based on Cowper-Symonds material law as given in Eq. (5) in which $\mathrm{D}=1.74 \times 10^{5} \mathrm{~s}^{-1}, \mathrm{q}=7.33$.

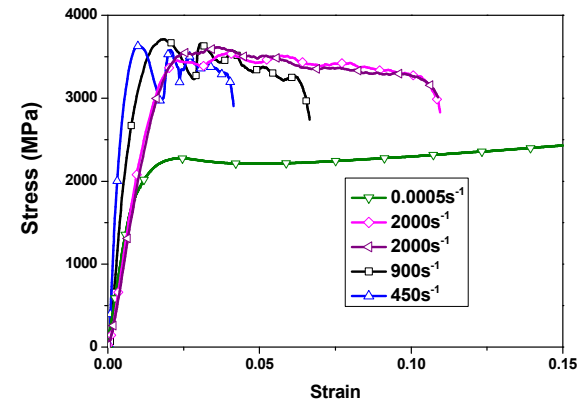

(a) Stress-strain curves

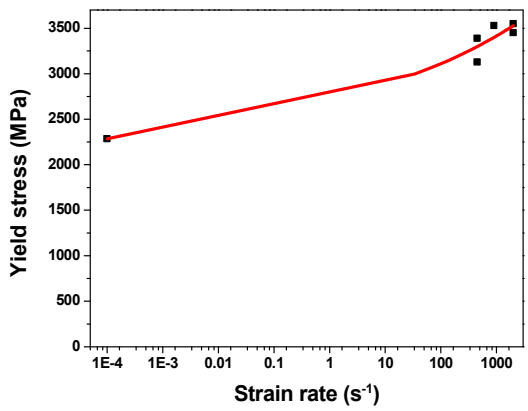

(b) Fitting by Cowper-Symonds law

Figure 6: Comparison of quasi-static and SHPB test results at ambient temperature.

The patterns of failure under dynamic and quasi-static loadings are significantly different at ambient temperature. Unlike the excellent ductile behaviour observed in quasi-static tests with strain more than $20 \%$, when the plastic strain reaches $2 \%$, axial splitting occurs in SHPB tests. For specimens with residual strain of $3.5 \%$, axial splitting throughout the specimen can be seen. For those with residual strain of $8 \%$, it is found that the specimens are severely damaged to several scattered pieces as shown in Figure 7. This is consistent with finding of other researchers. For example, Wang et al. found that while the material in quasi-static compressive tests had excellent deformability with a maximum strain of $14 \%$, when the strain approaches approximately $4 \%$, the stress dropped abruptly in dynamic tests [13]. 


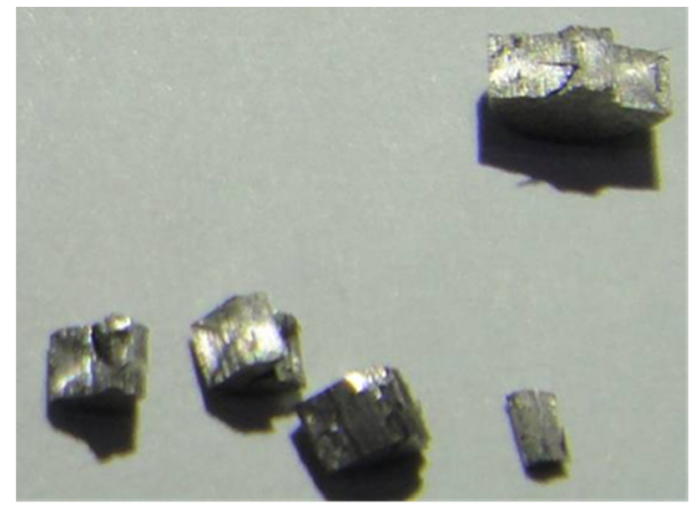

Figure 7: Fracture specimen from SHPB tests.

\subsubsection{Tests at elevated temperature}

SHPB tests on BMGC were carried out at various elevated temperatures up to $600^{\circ} \mathrm{C}$ for investigating the effect of temperature on mechanical properties of BMGC at high strain rate. The dynamic stress-strain curves at strain rate of $10^{3} \mathrm{~s}^{-1}$ with different temperatures are given in Figure 8 . It can be seen that the dynamic yield stress of the BMGC decreases with the elevation of temperature. Similarly to the quasi-static tests at elevated temperature, in high-temperature SHPB experiments, the stress-strain curves are found to soften after reaching the yield stresses as can be seen in Figure 8.

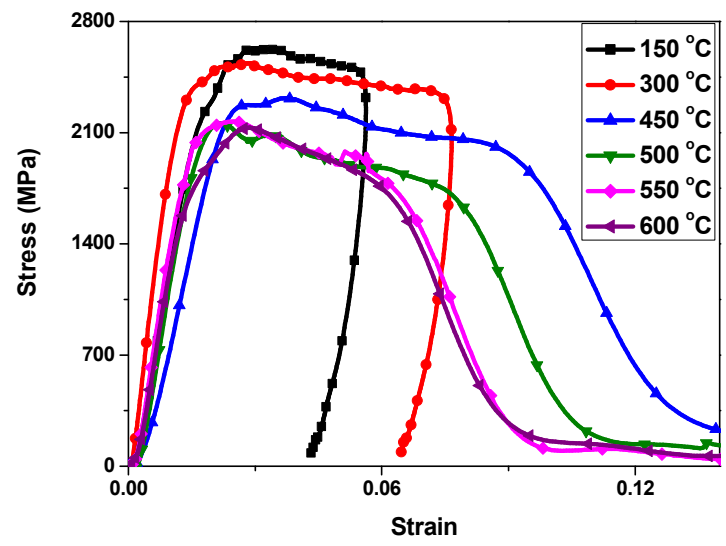

Figure 8: Comparison of stress-strain curves at strain rate of $10^{3} \mathrm{~s}^{-1}$ at different temperatures.

According to Figures 6 , for strain rate from $10^{2} \mathrm{~s}^{-1}$ to $10^{3} \mathrm{~s}^{-1}$, the variation in yield stress is not prominent at a specific temperature. Therefore, in the subsequent discussions about the thermal effects on the yield stress under dynamic tests, the divergence of strain rates in the SHPB tests at high temperature is not considered. 
The effect of temperature on the static and dynamic yield stresses of the BMGC material is illustrated in Figure 9. In the figure, the degradation relations of yield stress with regard to temperature for dynamic and static loadings are given with the dashed and solid lines, respectively, as follows

$$
\sigma_{T}=\sigma_{\text {room }}-\alpha \cdot \Delta T
$$

where $\sigma_{T}$ is the yield stress at elevated temperature in $\mathrm{MPa}, \sigma_{\text {room }}$ denotes the yield stress at ambient temperature of $20^{\circ} \mathrm{C}$ in $\mathrm{MPa}, \Delta \mathrm{T}$ is the change in temperature in ${ }^{\circ} \mathrm{C}$, and $\alpha$ represents the degradation of yield stress per unit degree Celsius. The mean value of 2.0 for $\alpha$ may be used as a universal deterioration coefficient as shown in figure 9 .

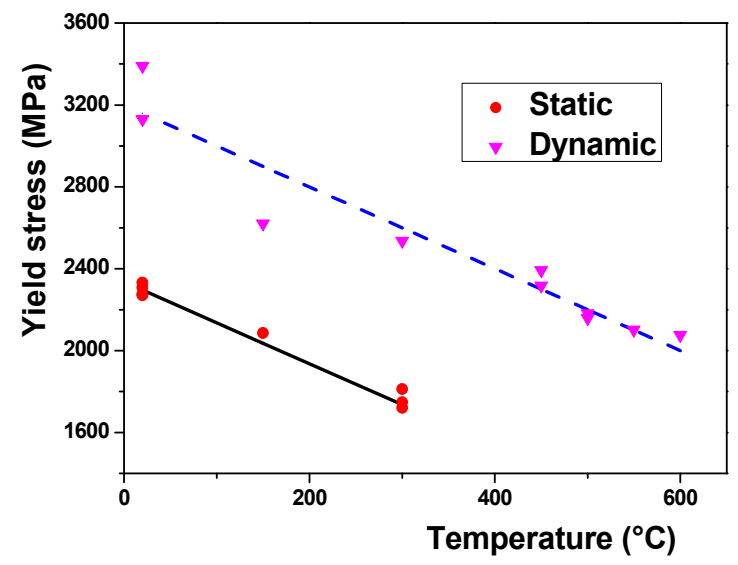

Figure 9: Temperature effects on the yield stress.

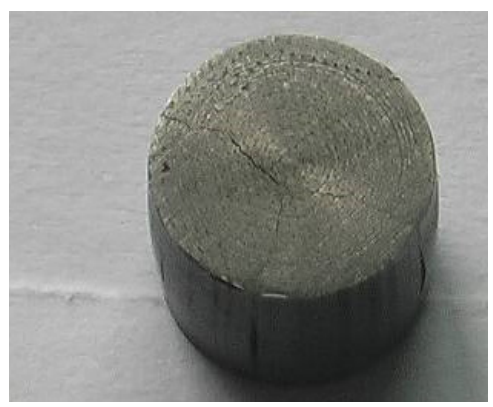

(a) $250 \mathrm{~s}^{-1}$

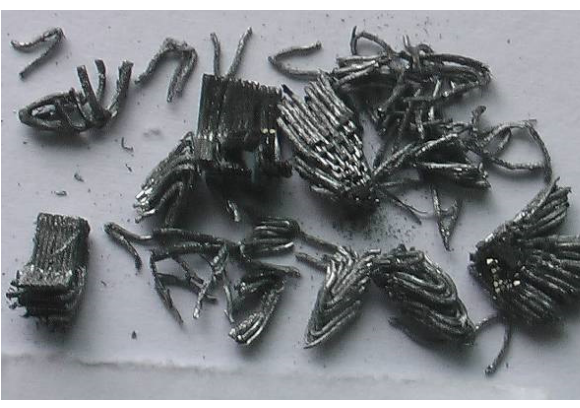

(b) $500 \mathrm{~s}^{-1}$

Figure 10: Comparison of failure formation at $450^{\circ} \mathrm{C}$ under different strain rates.

The damage and failure patterns at different strain rates are compared in Fig. 10. At a relatively small strain rate of $250 \mathrm{~s}^{-1}$, the specimen had axial splitting 
failure as shown in Fig. 10(a). When the strain rate increased to $500 \mathrm{~s}^{-1}$ and higher, the composite specimens are damaged severely with bending and buckling, as shown in Fig. 10(b).

\section{Conclusions}

This paper reports results from experimental studies of the mechanical properties of $80 \% \mathrm{~V}_{\mathrm{f}}$ tungsten fibre reinforced $\mathrm{Zr}$-based bulk metallic glass composite. The effects of strain rate and temperature on the yield stress are investigated in the present study. It is found that:-

At ambient temperature, BMGC material performs excellent deformation capability under static loading. At the train of $20 \%$, the specimen still keeps its load-carrying capacity. Axial splitting due to fibre deboning and formation of multiple hear bands in the BMG matrix are the dominate failure mode of the BMGC material. In dynamic tests at ambient temperature, failure occurs at a much smaller strain value although the dynamic strengths are $30 \%$ higher than those under static loading.

Both the static and dynamic strengths decrease with the elevation of temperature. In SHPB tests at high temperature, axial splitting is the characteristic failure pattern of specimen. The tungsten fibres were scattered and buckled with the increase of loading rate, this appearance may be used to explain selfsharpening behaviour of BMG composite penetrators.

\section{Acknowledgements}

Financial support from National Natural Science Foundation of China (Grant number 11572299 and 11302211) and the key subject "Computational Solid Mechanics" of CAEP for carrying out this study is acknowledged. The authors would like to thank Dr Yifei Hao of the Curtin University for his help and comments on the manuscript.

\section{References}

[1] Zhang ZF, Eckert J, Schultz L. Difference in compressive and tensile fracture mechanisms of $\mathrm{Zr}_{59} \mathrm{Cu}_{20} \mathrm{Al}_{10} \mathrm{Ni}_{8} \mathrm{Ti}_{3}$ bulk metallic glass. Acta Materialia 2003; 51: 1167-1179.

[2] Mukai T, Nieh TG, Kawamura T, Inoue A, Higashi K. Effect of strain rate on compressive behavior of a $\mathrm{Pd}_{40} \mathrm{Ni}_{40} \mathrm{P}_{20}$ bulk metallic glass. Intermetallics 2002; 10: 1071-1077.

[3] Louzguine DV, Kato H, Inoue A. High-strength Cu-based crystal-glassy composite with enhanced ductility. Applied Physics Letters 2004; 84:10881089.

[4] Choi-Yim H, Busch R, Köster U, Johnson WL. Synthesis and characterization of particulate reinforced $\mathrm{Zr}_{57} \mathrm{Nb}_{5} \mathrm{Al}_{10} \mathrm{Cu}_{15.4} \mathrm{Ni}_{12.6}$ bulk metallic glass composites. Acta Materialia 1999; 47: 2455-2462. 
[5] Conner RD, Dandliker RB, Scruggs V, Johnson WL. Dynamic deformation behavior of tungsten-fiber/metallic-glass matrix composites. International Journal of Impact Engineering 2000; 24: 435-444.

[6] Sun YF, Wei BC, Wang YR, Li WH, Cheung TL, Shek CH. Plasticityimproved $\mathrm{Zr}-\mathrm{Cu}-\mathrm{Al}$ bulk metallic glass matrix composites containing martensite phase. Applied Physics Letters 2005; 87: 051905.

[7] Bian Z, He G, Chen GL. Investigation of shear bands under compressive testing for Zr-base bulk metallic glasses containing nanocrystals. Scripta Materialia 2002; 46: 407-412.

[8] Qiu KQ, Wang AM, Zhang HF, Ding BZ, Hu ZQ. Mechanical properties of tungsten fiber reinforced $\mathrm{ZrAlNiCuSi}$ metallic glass matrix composite. Intermetallics 2002; 10: 1283-1288.

[9] Xie RZ, Zhang FJ, Yan YX, et al. High-temperature SHPB experimental technique and its application, explosion and shock waves, 2005, 25(4): 330334 (in Chinese).

[10] Zhang FJ, Xie RZ, Tian CJ, et al. Auto-Assembling Technique Used in High Temperature Experiment of SHPB, Journal of Experimental Mechanics, 2005, 20 (2): 281-284 (in Chinese).

[11] Chen G, Zhang QP, Huang XC. A method of incident pulse shaping for SHPB. WIT Transactions on The Built Environment 2014; 141: 181-189.

[12] Jones N. Structural impact. Ch8: strain rate sensitive behaviour of materials, Cambridge university press, second edition, 2012.

[13] Wang G, Chen DM, Shen J et al. Deformation behaviour of a tungsten-wire bulk metallic glass matrix composite in a wide strain rate range. Journal of Non-Crystalline Solids 2006; 352: 3872-3878. 